Historia y comunicación social

ISSN-e 1988-3056

https://dx.doi.org/10.5209/hics.66306

\title{
Inmigrantes del Perú en la prensa de Chile: El caso de La Estrella de Arica (2000-2010)
}

\author{
José Julián Soto Lara ${ }^{1}$; Pablo Chávez Zúñiga ${ }^{2}$; Janna Dallmann³
}

Recibido: 28 de septiembre de 2017. / Aceptado: 11 de septiembre de 2018.

Resumen. Se analizan noticias del diario La Estrella de Arica sobre los inmigrantes peruanos presentes en esa ciudad. La documentación, leída desde las teorías del análisis discursivo y de las representaciones sociales, sugiere que el periódico se sostiene ideológicamente en un racismo simbólico. La metodología funde procedimientos del análisis discursivo, puntualmente los referidos a los tópicos y las estrategias discursivas. Los resultados dan cuenta de ambas, las que transforman al inmigrante en un sujeto incivilizado. Se concluye que La Estrella construye sobre los inmigrantes, con sencillez discursiva, un tipo de otredad fundamentada en diferencias étnicas.

Palabras clave: Chile; inmigración peruana; prensa; Racismo simbólico; Arica.

\section{[en] Immigrants from Peru in the Chilean Press: the Case of La Estrella from} Arica (2000-2010)

\begin{abstract}
Articles published in the newspaper La Estrella from Arica about Peruvian immigrants present in this city are being analysed. The documentation, discussed within the theoretical framework of discourse analysis and social representations, suggests that the newspaper ideologically draws on "symbolic racism". The methodology integrates discourse analysis procedures, specifically those referred to topics and discursive strategies that transform the immigrant into an uncivilized subject. It is concluded that La Estrella constructs with discursive simplicity a type of elementary otherness in regard to the immigrant which is based on ethnic differences.
\end{abstract}

Key Words: Chili; Peruvian immigration; press; symbolic racism; Arica.

Sumario: Introducción. El racismo simbólico: discurso y representación. Metodología. Resultados. Conclusión. Referencias bibliográficas.

Cómo citar: Soto Lara, J. J.; Chávez Zúñiga, P.; Dallmann, J. (2019). Inmigrantes del Perú en la prensa de Chile: El caso de La Estrella de Arica (2000-2010), en Historia y comunicación social 24 (2), 649664.

\footnotetext{
1 Universidad Bernardo O'Higgins, Chile.

jose.julian.soto@gmail.com

2 Universidad de Chile.

pablo.chavez.zuniga@gmail.com

3 Universidad Autónoma de Barcelona.

Janna.dallmann@gmx.de
} 


\section{Introducción}

Esta investigación aborda desde la historia del tiempo presente (Bédarida, 1998; Fazio, 1998; Aróstegui, 2004) el discurso del diario La Estrella de Arica sobre los inmigrantes peruanos que la habitaron. Se interesa por la "peruanofobia" subyacente en ese periódico debido a su difusión en papel y digital en la frontera chileno-peruana. La Estrella, fundada durante la dictadura militar pinochetista, es producida ininterrumpidamente desde el 8 de febrero de 1976 hasta la actualidad.

Su periodismo "peruanófobo" construyó un conjunto de ideas y valores concretos hacia los inmigrantes de esa nación, que posibilitan detectar, describir y analizar cómo reprodujo un tipo de racismo: el simbólico. La Estrella apuntó a la creación de una "agenda temática" (McCombs y Shaw, 1972) sobre los inmigrantes, además de ofrecer tópicos estructurados concernientes a las consecuencias socio-culturales de ese flujo migratorio fronterizo.

Ese diario publicó noticias centradas en los inmigrantes relacionándolos con conductas, supuestamente, fuera de la norma legal o cultural chilena, como por ejemplo, el tráfico de drogas, la delincuencia, el ingreso ilegal al país, las conductas antihigiénicas, que sistemáticamente situaron al migrante en el campo de los antivalores chilenos. Pérez, citando a Van Dijk, ilustró desde un punto de vista económico esa táctica periodística sosteniendo que "lo que vende son las metáforas negativas sobre droga, racismo y violencia, contra-valores que refuerzan la exclusión, el abuso de poder" (2008: 2), trabajo de la prensa "popular" basada, en parte, en los elementos estéticos de la cultura popular (López, 1995: 24; Sunkel, 2001: 57; Randall, 2008: 28).

En Chile, estudios sobre la relación prensa de Arica, inmigración y otredades "nocivas" son escasos. Los realizados en Arica abordaron el problema tangencialmente (Araya, Rivas y Gasconi, 2000; Rivera, 2000). Fuera de ahí, Póo (2009) analizó la migración peruana desde la prensa capitalina; Browne y otros (2011) la producción de estereotipos antichilenos en un diario peruano y estereotipos antiperuanos en un diario chileno. Con una mirada sociológica y psicológica, un grupo mayor (Stefoni, 2002a, 2002b; Shiappacasse, 2008; Duchi y Rojas, 2010; Lahoz y Forns, 2016) han abierto una línea de investigación sobre las repercusiones sociales de esa migración. Liberona (2015) investigó en La Estrella de Iquique las imágenes construidas respecto a la inmigración boliviana.

Frente a esa carencia, esta investigación basada en fuentes hemerográficas, comprende las noticias como "ventanas" hacia el mundo que tienden a decirnos qué queremos saber, qué necesitamos saber y qué deberíamos saber (Rey, 2002: 15). O, en palabras formales, como "una secuencia del acontecer, producto de la interpretación contextual de un periodista que aplica criterios socialmente variables; que contienen [...] unos factores que la convierten en útiles a las personas" (Armentia y Caminos, 2003: 56).

Aunque no existe consenso en la definición de "noticia" (Martini y Luchessi, 2004; Gomis, 2008), aquellas nociones son claves para delimitar nuestro objetivo general: descubrir y analizar el racismo simbólico reproducido durante el periodo 2000-2010 por La Estrella. Para su consecución se proponen otros tres específicos. Establecer con claridad qué entenderemos por racismo simbólico, conceptualización discutida desde la teoría del análisis crítico del discurso y de las representaciones sociales. Identificar los tópicos preferentes publicados por La Estrella sobre los in- 
migrantes y en un nivel textual, distinguir las estrategias discursivas usadas por ese medio. Por último, valorar la eficacia periodística de La Estrella en la constitución de una representación social del inmigrante.

\section{El racismo simbólico: discurso y representación}

La discusión de las últimas décadas sobre el racismo distingue con claridad un racismo "viejo", clásico o tradicional de otro "nuevo", contemporáneo o simbólico.

Los orígenes del primero se sitúan en los siglos XV y XVI (Javaloy, 1994; Ward, 2000), durante la expansión colonial española. Las ideas de la superioridad racial blanca sobre la indígena maduraron hasta el siglo XIX, cuando con aportes de la biología se constituyó un cuerpo teórico explicativo de la "realidad" del racismo. Para Javaloy, los núcleos del racismo viejo fueron un "biologismo" caracterizado por aseverar una relación determinista entre los rasgos fenotípicos y las prácticas culturales y la "desigualdad de los humanos", fundamentada en una jerarquía creada por el color de la piel. En un sentido similar, Bethell (2000) identificó las dos fuentes del racismo decimonónico europeo, que pueden explicar el racismo latinoamericano de esa época: una búsqueda de las particularidades de una "raza" nacional homogénea culturalmente y diferente de otras y, también, la constatación empírico-antropológica de una "degradación" de los "otros".

Javaloy sostiene que las consecuencias del racismo nazi derribaron ese paradigma eugenésico en Occidente; allí se transfiguró en un racismo simbólico que "no confiesa directamente su naturaleza, que se niega a declarar expresamente su tendencia a discriminar al negro y se refugia en sobreentendidos, supuestos y afirmaciones implícitas [siendo] sutil e indirecto" (1994: 23). La fórmula, explicó, pone a disposición del racista el beneficio de presentar su ideología dentro de los marcos compatibles con las normas de tolerancia e igualdad que exigen las democracias actuales.

Espelt y Javaloy (1997) identificaron los principios básicos del racismo nuevo: el reconocimiento de que moralmente es reprochable; la certeza de que la discriminación racial es un hecho del pasado; la opinión de que las minorías afectadas hacen demandas injustas y reciben más atención y recursos de los merecidos. Cárdenas (2007), sugiere que en éste se acentúa la naturaleza ideológica del prejuicio, desarrollándose conductas en contra de los discriminados desde un plano simbólico y violento. En el extremo, si el racismo viejo se identificó por su política agresiva contra las "razas" inferiores a la blanca, el nuevo es ambivalente en su tolerancia hacia el "otro" (Huici, 1996; Wieviorka, 2002; Hogg y Vaughan, 2008), y sostiene que no existen razas superiores o inferiores sino diferentes lo cual imposibilita el diálogo para convivir (Espina, 2004). Igualmente, en su forma simbólica, ese racismo carece de conciencia frente a sus prácticas pareciendo inofensivo (Pérez, 1996; Almeida, 1999).

Tales concepciones sobre el racismo simbólico son atingentes a un sistema social de desigualdad étnica donde el discurso, compuesto por los planos sociales y cognitivos (Van Dijk, 2000), tiene centralidad. El subsistema social comprende las discriminaciones cotidianas agrupadas en dos niveles: un micronivel que incluye las prácticas diarias de discriminación y otro macronivel donde se sitúan, principalmente, las organizaciones, disposiciones legales y las instituciones. El subsistema cognitivo 
está compuesto por las creencias de los grupos (conocimientos, actitudes, normas y valores e ideologías). La relación entre esos subsistemas es dialéctica, puesto que los usuarios de los discursos "además de estar sujetos a las restricciones sociales del mismo, también contribuyen a él, lo construyen o lo modifican” (2000: 46).

En el subsistema cognitivo las ideologías - como el racismo simbólico- son vitales porque, como explicó Van Dijk, organizan opiniones generales de los grupos frente a temas considerados importantes. Las ideologías influyen en el "conocimiento específico y en las creencias de los individuos usuarios del lenguaje" (Van Dijk, 1996: 19). Al mismo tiempo, las ideologías continúan transformándose, situación que permite al autor sugerir que éstas reflejan una estructura de polarización social entre el grupo identificado como "nosotros" en contraposición a los "otros" (Van Dijk, 1996: 18).

Van Dijk explicó cómo la elaboración de discursos escritos dentro de un contexto social público pone de relieve la intención de argumentar puntos de vista. Ve en eso una dimensión "pragmática" del lenguaje. Así, en general, "un fragmento de una noticia funcionará como una afirmación” (Van Dijk, 1983: 82). Por tal razón, decía, los discursos no deben examinarse como objetos, sino más bien como "fragmentos de una acción social" (Van Dijk, 1983: 83).

Aquí entenderemos el acto afirmativo como una función específica del lenguaje escrito en los periódicos. Renkema (1999) demostró cómo con la función apelativa del lenguaje, aplicada a la prensa, los lectores deben ser convencidos de determinadas ideas. Así, el objetivo de los discursos apelativos es un cambio de actitud en el receptor: "Una definición popular describe la actitud como las evaluaciones generales que hace la gente con respecto a sí misma, a otra gente, a objetos y temas. Estas evaluaciones generales se consideran un determinante clave de la conducta. Al cambiar las actitudes, los comunicadores esperan cambiar la conducta de los receptores" (1999: 164). Pensando específicamente en la posición marginal de los inmigrantes peruanos en la producción de relatos públicos sobre ellos mismos, bien pueden ser un grupo sin "poder de identificación” (García, 2012).

¿Qué aparatos teóricos ayudan a comprender las formas en que el racismo simbólico, codificado en discurso periodístico, se desenvuelve en los mass media? La teoría psicosocial de las representaciones sociales hace posible que los mecanismos inherentes al lenguaje escrito logren establecer, con alta definición, un conjunto de ideas y símbolos socialmente compartidos sobre el racismo. Dejando de lado cualquier naturalismo, esta teoría parte de una premisa "constructivista" (Avendaño, Krause y Winkler, 1993: 108) e histórica para observar sus objetos de análisis.

La teoría de las representaciones sociales o, como se ha venido refiriendo en los últimos años, de las "representaciones", ha sido construida por varios epígonos del pensamiento de Moscovici para quien aquellas eran "una modalidad particular del conocimiento, cuya función es la elaboración de los comportamientos y la comunicación de los individuos" (Moscovici, 2007: 10).

Las representaciones permiten comprender cómo la sociedad llega a pensar sobre uno o varios temas fundamentales para la misma; quienes favorecen la visibilidad de éstos, así como la invisibilidad de otros; mediante qué canales de comunicación se transmiten los conocimientos que permiten tales pensamientos, etc. Esas consideraciones nos sitúan en la cuestión de cómo el poder escritural puede fabricar representaciones adjudicando valores identificables a grupos extranjeros (inmigrantes peruanos), aportando insumos discursivos al racismo simbólico. 
Para Jodelet y Guerrero (2000) las representaciones sociales son programas de percepción. A diferencia del conocimiento científico, éstas son concebidas como conocimientos de una "teoría ingenua" que facilita la lectura de la realidad donde se desenvuelven los grupos que las poseen. A la vez, pueden constituir sistemas de significaciones que tienen por función interpretar secuencias de acontecimientos del mundo social. Esos investigadores acentúan el papel fundacional que tienen los discursos circulantes en el espacio público para las representaciones sociales. De tal modo las representaciones "funcionan como un lenguaje en razón de su función simbólica y de los marcos que proporcionan para codificar y categorizar lo que compone el universo de la vida" (2000: 10).

Esa categorización está vinculada a los tres tipos de representaciones planteadas por Moscovici (Perera, 2003: 6), según el grado de importancia social de las mismas: "hegemónicas" (gozan de un alto grado de consenso grupal), "emancipadas" (al no ser hegemónicas sólo se encuentran en subgrupos sociales) y "polémicas" (las cuales se encuentran en abierta disputa por grupos en conflicto). Todas ellas, aunque diferencialmente, tienen estabilidad al ser parte del "entorno social simbólico en el que viven las personas" (Marková, 2006: 163) construido y reconstruido, principalmente, por medio del lenguaje.

Abric (2001), en un enfoque similar al de Jodelet y Guerrero, propone comprender las representaciones como visiones funcionales del mundo. De ese modo, individuos y grupos pueden ser favorecidos con ellas, porque sus contenidos facilitan y confieren el sentido de las conductas y el entendimiento de una realidad autoreferida (2001: 13). Ese espacio vital "real", también puede ser analizado como un "sistema cognitivo", donde es posible "reconocer la presencia de estereotipos, opiniones, valores y normas que suelen tener una orientación actitudinal positiva o negativa" (Araya, 2002: 11).

De la yuxtaposición entre representaciones, discurso y racismo simbólico es viable pensar que la prensa aquí estudiada, interesada más por fenómenos inmediatos que por explicaciones históricas, sea una fuente donde se encuentren elementos del racismo simbólico que, devenido en discursividades escritas, colabora institucionalmente construyendo representaciones sobre hechos de relevancia histórico-social como la migración y sus actores.

\section{Metodología}

Sugerir la existencia de racismo simbólico en La Estrella obliga probar en un modelo metodológico ad hoc las fuentes recopiladas. Los criterios cronológicos para seleccionarlas fueron el aumento de inmigración peruana en Arica y la fecha de disponibilidad del diario en internet ( 8 de diciembre de 2000), finalizando la recopilación una década después. Las noticias que componen la muestra indicaron en sus corpus las palabras "peruanos" o "inmigrantes", así como sus derivaciones semánticas.

Van Dijk (1996) sostuvo que la prensa neoracista tiene preferencia por seis tópicos, entre los que se encuentran las descripciones: autoidentitarias, de propósitos, de normas y valores, de posición y relación, de actividad y de los recursos. La Estrella prescinde de autoreferencias absolutamente positivas, por tal razón hemos excluido las dos últimas descripciones relacionadas con tales aspectos. Van Dijk también detectó doce estrategias discursivas de la prensa, en un nivel estrictamente textual, para referirse a las otredades étnicas (Cuadro $n .^{\circ} 1$ ). 
Cuadro n. ${ }^{\circ} 1$

\begin{tabular}{|c|c|}
\hline \multicolumn{2}{|c|}{ Tópicos y estrategias discursivas } \\
\hline Tópicos & Características \\
\hline Descripciones autoidentitarias & $\begin{array}{l}\text { Se expresa en las noticias la respuesta a } \\
\text { ¿Quiénes somos? Y se evidencian argumen- } \\
\text { tos delimitativos en relación a los "otros". }\end{array}$ \\
\hline Descripciones de propósitos & $\begin{array}{l}\text { Las actividades adquieren un sentido ideo- } \\
\text { lógico y social sólo si tienen propósitos po- } \\
\text { sitivos, por lo que el discurso de "nuestras" } \\
\text { actividades se vuelve central. }\end{array}$ \\
\hline Descripciones de normas y valores & $\begin{array}{l}\text { Para el discurso racista es crucial referirse } \\
\text { a las normas y los valores de lo que "noso- } \\
\text { tros" consideramos bueno o malo, correcto } \\
\text { o erróneo. Describir al "otro" supone enfa- } \\
\text { tizar la violación de las normas y valores. }\end{array}$ \\
\hline Descripciones de posición-relación & $\begin{array}{l}\text { Los grupos definen su identidad y propósi- } \\
\text { tos con relación a otros grupos. En este tó- } \\
\text { pico se enfatizan las relaciones grupales con } \\
\text { conflicto y la presentación negativa del otro. }\end{array}$ \\
\hline Estrategias discursivas & Características \\
\hline Lexicalización negativa & $\begin{array}{l}\text { Se seleccionan palabras fuertemente ne- } \\
\text { gativas para describir las acciones de los } \\
\text { "otros". }\end{array}$ \\
\hline Hipérbole & $\begin{array}{l}\text { Se describen los acontecimientos de los } \\
\text { "otros" en términos muy exagerados. }\end{array}$ \\
\hline Móvil de compasión & Se compadece de las víctimas de los "otros". \\
\hline Móvil de altruismo aparente & $\begin{array}{l}\text { Llamado así porque generalmente no se } \\
\text { concluye el argumento y sólo tiene una fun- } \\
\text { ción de denegación y de auto-presentación } \\
\text { positiva, debido a que el altruismo es un va- } \\
\text { lor positivo. }\end{array}$ \\
\hline Móvil de honestidad aparente & $\begin{array}{l}\text { Se utilizan expresiones tales como "a decir } \\
\text { verdad", "francamente", "no debemos ocul- } \\
\text { tar la verdad", etc. para luego realizar dene- } \\
\text { gaciones sobre la conducta de los "otros". }\end{array}$ \\
\hline Comparación negativa & $\begin{array}{l}\text { Se acentúan los atributos negativos del } \\
\text { "otro" comparándolo con personas o grupos } \\
\text { reconocidos generalmente como "malos". }\end{array}$ \\
\hline Generalización & $\begin{array}{l}\text { Se generaliza la actitud de una persona o } \\
\text { grupo restringido hacia una categoría o gru- } \\
\text { po más amplio. }\end{array}$ \\
\hline Concretización & $\begin{array}{l}\text { Se acentúan los aspectos negativos de los } \\
\text { "otros" realizando descripciones concretas } \\
\text { y visualizables (fotografías). }\end{array}$ \\
\hline
\end{tabular}




\begin{tabular}{|l|l|}
\hline Aliteración & $\begin{array}{l}\text { Se apoya la retórica con la fonología para } \\
\text { subrayar la importancia de palabras clave. }\end{array}$ \\
\hline Advertencia & $\begin{array}{l}\text { Se enfatizan las amenazas y el terror que } \\
\text { provocan las actividades de los "otros". } \\
\text { Abundan los escenarios catastrofistas. }\end{array}$ \\
\hline Violación de las normas y valores & $\begin{array}{l}\text { Distinguirse de los "otros" no es sólo escri- } \\
\text { bir reseñas positivas sobre la mismidad. En } \\
\text { efecto, esta estrategia enfatiza las violacio- } \\
\text { nes de las normas y valores que hacen los } \\
\text { "otros" con "nuestra" cultura. }\end{array}$ \\
\hline Presuposición & $\begin{array}{l}\text { Se enfatizan indirectamente "nuestros" atri- } \\
\text { butos apelando al sentido común evitando } \\
\text { así un análisis riguroso de los mismos. }\end{array}$ \\
\hline
\end{tabular}

Fuente: Elaboración de los autores. Adecuación basada en Van Dijk (1996).

Un total de 436 noticias fueron examinadas a la luz de esos tópicos y estrategias discursivas, analizándolas y clasificándolas con el objetivo de elaborar una tipología del inmigrante en Arica. El primer análisis (tópicos) y el segundo (estrategias) consideró la noticia como unidad de base realizando una "codificación holística" (Alonso, Volkens y Gómez, 2012: 21), optando por el documento entero. Contrario a toda complejidad en la elaboración del racismo simbólico, la prensa privilegió en un elevadísimo porcentaje del total de noticias (Gráfico n. ${ }^{\circ}$ 1) los tópicos y estrategias referidos a las descripciones de normas y valores y a las violaciones de las normas y los valores de la cultura chilena.

Gráfico n. ${ }^{\circ}$ 1: Principales sub-tópicos derivados de las descripciones de normas y valores

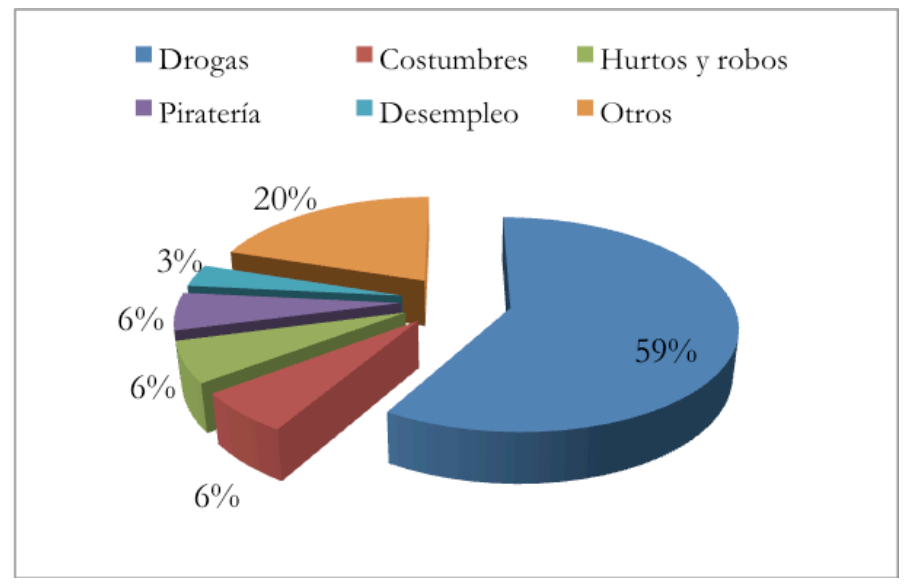

Fuente: Elaboración de los autores.

Un tercer análisis centrado sólo en los titulares de las noticias demuestra la importancia concedida al tráfico de drogas (Gráfico n. ${ }^{\circ}$ 2). El titular "máximo nivel de la macroestructura informativa [...] puede resultar fundamental si lo que se busca es influir de un modo determinado en los lectores" (Sánchez, 2010: 82), por ello identificar su peso cuantitativo de modo particular resulta fundamental. Los aspectos que siguen en importancia al tráfico de drogas no superan el 10\% de esa misma variable: 
Gráfico n. ${ }^{\circ}$ 2: Aspectos recurrentes en los titulares

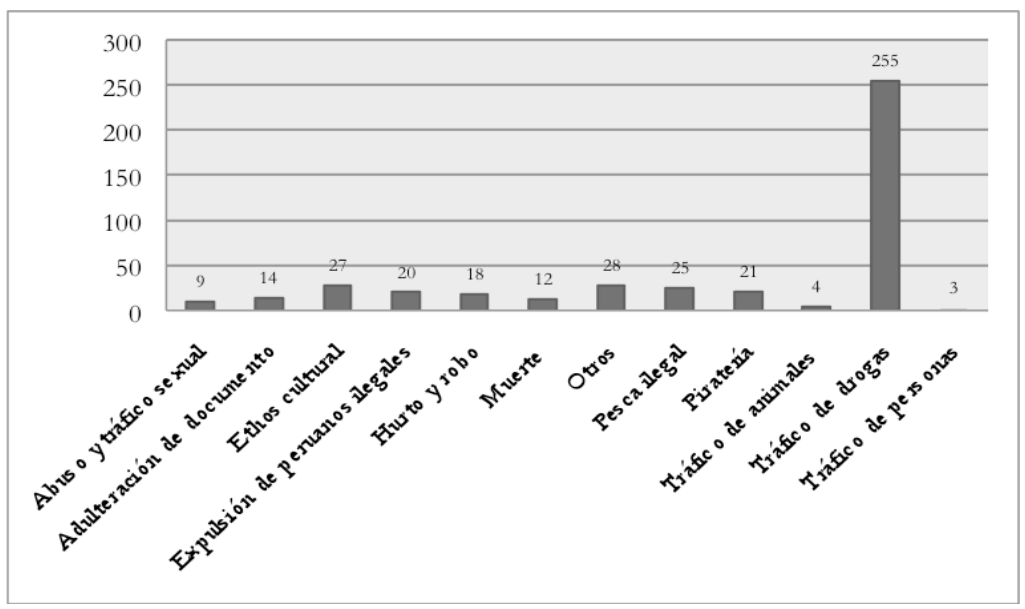

Fuente: Elaboración de los autores.

\section{Resultados}

Los tópicos construidos por La Estrella (en adelante $L E$ ) hacen imprescindible categorizar un grupo de cinco descripciones de normas y valores atentatorias contra la cultura e institucionalidad chilena: el tráfico de drogas, el ethos cultural, el robo, la piratería y, por último, el causante de desempleo (la categoría "otros" agrupó noticias referidas al uso de documentación falsa, a la pesca ilegal, al tráfico de animales, entre otros). Cada tema va acompañado de citas que indican las estrategias discursivas.

El tráfico de drogas fue la práctica social de los inmigrantes más tematizada con una periodicidad cotidiana. La escritura individualiza al inmigrante, reconociendo su identidad nominal y citadina (Tacna, Puno, Arequipa, etc.). Al mismo tiempo se constata la intención de denominar esta actividad con localismos. Por ejemplo, el tráfico "hormiga" (pequeñas cantidades de drogas) de los "burreros" (quienes transportan droga).

La criminalización del inmigrante que transporta drogas (cocaína, pasta base, marihuana, heroína, etc.) tiene como contrapartida la magnificación de la Policía. Las legitimaciones de esa institución se sirven de frases como: "pero la policía le seguía los pasos y pudo detenerlos cuando se procedía a efectuar la transacción" ( $L E$, "Detectan tráfico en Chacalluta", 11 de marzo de 2001, p. A-11), "Detenidos 4 narcos peruanos. Suma y sigue la labor de antinarcóticos" ( $L E$, "Detenidos cuatro narcos peruanos", 16 de abril de 2001, p. A-8), "Exitosa resultó operación Isla El Alacrán" (LE, "En envío de paltas ocultaban drogas", 19 de mayo de 2001, p. A-9), "Cuatro diligencias positivas del OS7 de Carabineros" ( $L E$, "Nueve detenidos por microtráfico", 9 de mayo de 2001, p. A-13), "Operación junio de la BRIAN de Investigaciones" (LE, "El golpe más duro del año", 14 de junio de 2001, p. A-9). 


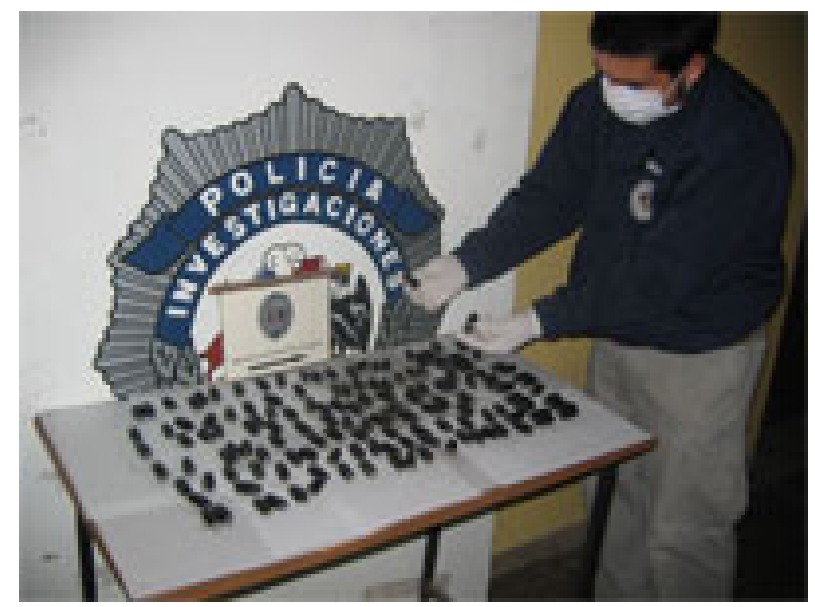

Imagen n. ${ }^{\text {1. " }}$ "El sistema de transportar la droga en ovoides en el estómago o en la vagina es usado en forma frecuente por los burreros peruanos". Fuente: $L E$, "En prisión peruanos que transportaban droga", 19 de marzo de 2006, p. A-9.

Algunas noticias incluían mensajes de desagrado por la reiteración del fenómeno. Frases del tipo "otra vez un peruano detenido" o "de nuevo cayó una banda de burreros", expresaron una molestia hacia éstos y, puede desprenderse, fueron una incitación a la acción de las autoridades.

El ethos cultural "bárbaro" del inmigrante fue otro aspecto tematizado. El racismo simbólico afecta las costumbres de quienes lo padecen, pues así castiga la totalidad de sus modos de vida. En Arica, la aglomeración de inmigrantes en torno al Terminal Internacional de Locomoción Colectiva, favoreció la "guetización" de ese espacio. Ese punto de encuentro chileno-peruano influyó en la trama social y urbana del sector.

Se ironizó, también, sutilmente la condición de "turista" del inmigrante, categoría legal con que ingresa a Chile. Noticias del siguiente estilo demuestran lo dicho: "A más de algún turista le habrá llamado la atención la cantidad de población peruana que se ve a diario en las calles ariqueñas, dándole a nuestra ciudad una característica cosmopolita muy particular. Sin embargo, la mayoría de estas personas no está aquí por motivos turístico o legales" (LE, "El Terminal de los peruanos", 18 de marzo de 2001, p. A-13) o ridiculizaciones como la siguiente: "La calle Diego Portales, a la altura del Terminal Internacional [...] se ha convertido en una verdadera agencia de empleo. Los días lunes, se concentra la mayor cantidad de «turistas peruanos» quienes se desempeñan en diferentes áreas" ( $L E$, "El cara y sello de la convivencia fronteriza", 10 de febrero de 2002, p. A-13).

Otra práctica del inmigrante donde se enfatizó la violación del civismo chileno fue la sexualidad desarrollada en espacios públicos. Esa tarea incluyó descripciones testimoniales de vecinos para otorgar credibilidad al relato. La exasperación chilena, debido a la afectación realizada por los peruanos a la moral, fueron traducidos a noticias que censuraban el diario vivir de los mismos. Un vecino contó que "hace unos días vio a una pareja manteniendo relaciones sexuales a las 8 de la mañana" ( $L E$, "Negocio de las baterías molesta a los vecinos", 11 de octubre de 2004, p. A-3). Otra 
nota apuntó "la conducta inmoral de algunos de estos extranjeros que, según dijeron los vecinos, tienen relaciones sexuales en el puente que cruza el lecho de este río" (LE, “Quejas por contaminación y actos inmorales", 14 de octubre de 2004, p. A-11).

La prensa sintetizó las molestias alineándose con los chilenos y juzgando a los inmigrantes (apodados despectivamente "cholos"): "el barrio tiene que aguantar que varios de ellos utilicen el área como baño público e, incluso, los más osados lo ocupen como nido de amores furtivos" ( $L E$, "Quieren acabar con suciedad", 15 de octubre de 2004, p. A-3). Por último, sobre los hoteles de bajo costo donde algunos hospedaban afirmó: "la comodidad no es la característica principal del lugar, según cuenta, con series de colchonetas una al lado de otra, donde reina la promiscuidad y más de alguna madre ha nacido en las acaloradas estadías" ( $L E$, "El Terminal de los peruanos", 18 de marzo de 2001, p. A-13).

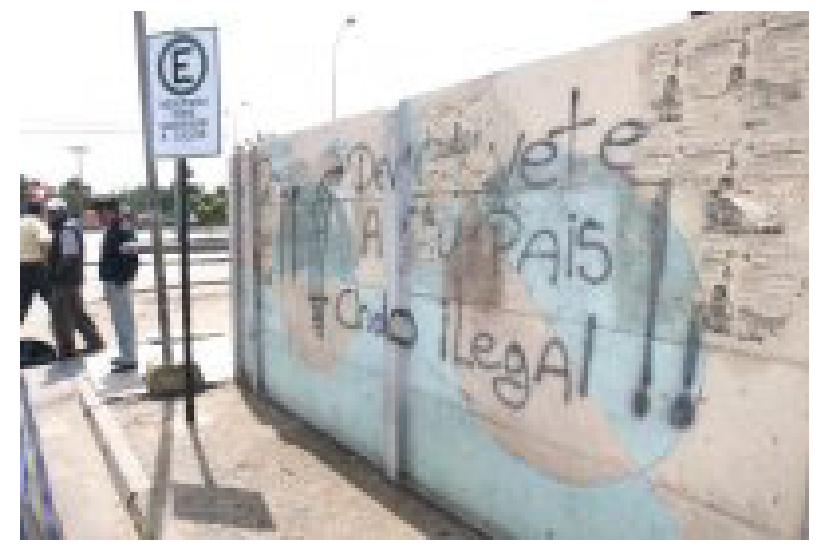

Imagen n. ${ }^{\circ}$ 2. "Devuélvete a tu país cholo ilegal", Fuente: $L E$, "Rayados racistas se perpetuaron”, 24 de septiembre de 2008, p. A-4.

Un tercer aspecto tematizado fueron los robos y hurtos de artefactos con gran valor para la comunidad afectada, sobresaliendo automóviles, computadoras, móviles, bicicletas, billeteras, etc. Un lugar de venta ilegal eran los contornos del Terminal Internacional, situación que favoreció la creación periodística de un espacio pernicioso donde, incluso, se podía encontrar a los "ladrones" ofertando las especies.

En la criminalización del inmigrante el papel policial tuvo una función similar a la ocupada en el tráfico de drogas. Sin embargo, a diferencia de ese, los robos y hurtos fueron trabajados por la prensa con matices irónicos o caricaturescos hacia los inmigrantes y, también, dudando de las escasas declaraciones realizadas en las entrevistas concedidas por ellos. Una nota explicó el desenlace de una pareja de ladrones peruanos:

Marta Pinto Mendoza y Lorenzo Fernández Vilches habían arribado a nuestra ciudad con el único propósito de hacerse unos pesos extras. No obstante, ambos extranjeros, oriundos de la ciudad de Arequipa, decidieron cumplir su objetivo delinquiendo a través del denominado robo hormiga, en las ferias locales. Ambos habían planificado detalladamente la forma de trabajar: la idea era recorrer las galerías del centro y aprovechar al máximo los descuidos de los clientes, a fin de hurtar especies. El plan no tenía márgenes de errores. Sin embargo, ninguno de los 
extranjeros pensó que en la tarde del viernes sus andanzas llegarían abruptamente a su fin, luego que una de sus propias víctimas, quien es detective de la Policía de Investigaciones, los detuviera tras una breve persecución ( $L E$, "Peruanos robaron a mujer detective", 10 de abril de 2005, p. A-10).

Otro ámbito lo conforman las noticias referidas a la piratería. La adulteración de marcas era realizada en el Perú introduciéndose objetos ilegalmente por Arica hacia el resto de Chile. Ese circuito permite que el país de origen de las mercancías, así como los contrabandistas sean sometidos al juicio periodístico. A la vez, este delito permite referirse a la disputa económica secular entre las economías de Tacna y Arica. En el periodo estudiado, como la bonanza económica favoreció a la ciudad peruana, la prensa encontró espacio para culpabilizar, en parte, al comercio tacneño: "La piratería de nuestra ciudad tiene un nombre y un apellido: Tacna" ( $L E$, "Lo más pirateado", 5 de mayo de 2010, p. 23).

La Estrella valoró la eficacia policial contra los "piratas" impresionándose cuando la justicia liberó a los inmigrantes detenidos por tal razón. En su lucha contra el comercio ilegal, identificó los lugares donde se vendían esos productos. Su interés moralizante apeló a la movilización contra la piratería llamando a tener "Mano dura con el comercio pirata" (LE, 8 de marzo de 2009, p. A-10), y entendiendo las fiscalizaciones sobre los inmigrantes sospechosos como una "Guerra sin cuartel a la piratería" (LE, 12 de marzo de 2009, p. A-10).

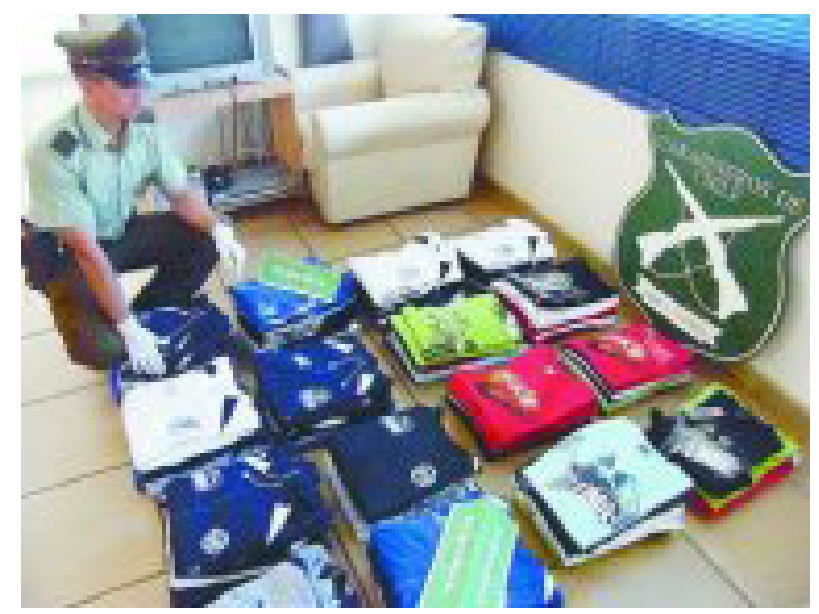

Imagen n. ${ }^{\circ}$ 3. Fuente: $L E$, "Detenida por vender ropa falsificada", 25 de abril de 2009, p. A-10.

Por último, el diario cedió espacio a quienes sostuvieron que la presencia de inmigrantes causaba desempleo. En una década de noticias se constata esa "transferencia" a parlamentarios pertenecientes a la derecha política quienes sostuvieron: "los inmigrantes ocupan los puestos de trabajos de los chilenos" ( $L E$, "Ilegales: la espina del desempleo", 12 de diciembre de 2000, p. A-5) y, con mayor detalle, "En la poblaciones un $80 \%$ de los jefes de hogar está sin empleo, siento los principales responsables la falta de iniciativa del gobierno y la fuerte presencia de extranjeros que ocupan los puestos de trabajo de los connacionales" ( $L E$, "Desempleo: las explicaciones sobran", 29 de abril de 2001, p. A-3). 
Probablemente esa campaña periodística coadyuvó, desde la crítica, para la implementación de políticas diseñadas a reducir el impacto "negativo" de la inmigración. Ello se podría relacionar también con las expulsiones de inmigrantes donde, una vez más, la prensa reafirmó el papel policial y de la seguridad ciudadana al publicar sobre la expulsión de "expulsan a extranjeros ilegales" ( $L E, 4$ de septiembre de 2002, p. A-8), la existencia de "1500 peruanos ilegales en Arica" ( $L E, 30$ de junio de 2002, p. A-13) y, en efecto, reporteando el decreto de "expulsión para 26 peruanos" (LE, 6 de junio de 2003, p. A-8).

\section{Conclusión}

Seleccionamos La Estrella para estudiar el fenómeno del racismo simbólico en Arica. Su nombre remitía a uno de los simbolismos patrios más extendidos en Chile: la estrella solitaria de la bandera nacional. Esta cuestión de emblemas hacía sospechosa a priori su creatividad para elaborar otredades primarias históricamente rivales del país como es el caso de la peruana.

El origen de esa desavenencia nacionalista debe rastrearse en la Guerra del Pacífico donde Chile enfrentó a la alianza Perú-boliviana. Si bien los años de combate no superaron los cinco (1879-1884), la posguerra -donde Perú cedió a Chile la ciudad de Arica- ha durado, a juzgar por los diferendos territoriales entre Chile-Perú en la Corte Internacional de Justicia de La Haya, hasta la actualidad.

Esa prolongación friccionada de la diplomacia chileno-peruana nos permitió pensar en un macro-contexto binacional-cultural donde se insertan y desarrollan las prácticas sociales de colisión simbólica (no necesariamente militar o diplomática). Una de ellas es la producción periodística.

La lectura de cientos de noticias permitió constatar a posteriori la utilización de una escritura referida, casi con exclusividad, a la violación de las normas y los valores de Chile por parte de los inmigrantes. Esa estrategia discursiva, en desmedro de otras alternativas que tienen las prensas racistas, privilegió La Estrella. Al apelar a los comportamientos que vulneran "normas" y "valores" se juzgó con simpleza dos conceptos fundamentales para la filosofía, la antropología, la sociología y la historia. Para el diario, la genealogía de esas normas y valores no es prioridad por lo que no hubo análisis fragmentarios, sino sólo la constatación de que grupos inmigrantes las zaherían.

Notamos, por eso, una reacción de La Estrella apreciable en la marginación del inmigrante. No debe escamotearse un hecho: la estrategia de la violación de las normas y valores es también una acusación grave que insiste en las diferencias culturales insuperables entre chilenos y peruanos. Esa brecha fue reproducida con insistencia, consolidando y definiendo los campos simbólicos de lo civilizado (chileno) e incivilizado (peruano).

La banalidad del establecimiento de la anormalidad del inmigrante puede comprenderse desde otro ángulo. Por ejemplo, con el uso mínimo de otras estrategias (lexicalización negativa, hipérbole, comparación negativa, aliteración o advertencia). Éstas requieren un mayor trabajo editorial. Las dos primeras fueron excluidas debido al riesgo de presentarse como un diario racista per se. Las restantes requieren conocimientos acerca de la historia global; de conocimientos sobre retórica y fonología $\mathrm{y}$, por último, de una imaginación prodigiosa para ensayar escenarios futuros como 
consecuencia de la inmigración. En el caso de las estrategias marcadamente relacionales, es decir, que contactan chilenos con peruanos, pareciera ser que La Estrella prefiere separar ambos grupos para no sugerir hibridaciones.

Los tópicos fabricados demostraron que los actos inmigrantes contrarios a las normas y valores chilenos predominaron en la prensa. Una mayoría de noticias referidas a aquellos hicieron difícil identificar otros tópicos (descripciones autoidentitarias, de propósitos, de posición-relación). El proceso configurante de una imagen del inmigrante en función de los temas publicados aportó los insumos ideológicos para "sedimentar" su peligrosidad. Fue difícil ubicar descripciones autoidentitarias chilenas que, por comparación, se refiriesen al inmigrante. A decir verdad, las descripciones de la "chilenidad" se pueden encontrar en otras secciones del diario. Al igual que la identidad migratoria, aquella es entregada por aglomeración informativa sin marcos prefijados. Esa misma situación corresponde a la descripción de propósitos. Por último, en la relativa a las descripciones de posición-relación sólo constatamos noticias preocupadas por las dificultades de las relaciones vecinales entre inmigrantes y vecinos, las que en comparación con las referidas al tráfico de drogas, fueron mínimas.

Las fuentes hemerográficas investigadas permitieron dialogar con la teoría de las representaciones sociales. Como ha sido tradición en este campo de estudio, la recolección de artefactos concretos -noticias- neutraliza el riesgo de la reflexión enclavada en ideas puras. Esa heurística tuvo por objetivo recolectar noticias relacionadas a las prácticas sociales de los inmigrantes durante una década. De esa forma se consideró con certeza la constitución construida e histórica de las representaciones que permiten pensar al migrante.

Esas permiten al endogrupo comunicarse al compartir ideas semejantes sobre el exogrupo. La magia de la escritura periodística referida a los peruanos pudo actuar sobre la cognición del lector. La lectura de noticias, es probable, permitió asociar conceptos situados en una red de ideas afines con la inmigración. Esa magia escritural se puede efectuar en coalescencia de palabras emocionales las que mezcladas con otras de menor carga sentimental forman juicios de valor. Por eso no sería extraño que debido al peso cuantitativo de las noticias sobre drogas, el inmigrante aun cuando no esté implicado en ese negocio se piense bajo esos términos delictivos. En ese estado se comprende, sin lugar a dudas, cómo las representaciones constituyen "programas de percepción" o "teorías ingenuas" para hacer menos compleja la "lectura" de la vida.

No cabe duda que las representaciones periodísticas hacia los migrantes tienen un estatus "hegemónico", pues son aceptadas y poco criticadas, produciendo en secuencia otros disvalores que componen la identidad migrante peruana en Chile. Así, es imposible pensar que el producto de la prensa tenga, al contrario, un sello representacional "emancipado" o "polémico".

De lo dicho hasta ahora parece ser cierto que las representaciones sobre los inmigrantes los "anormalizan" sin discursos explícitamente fóbicos. En las noticias se ausentan palabras, oraciones, corpus, titulares, etc. con contenidos nacionalistas, xenofóbicos o etnocéntricos. La sutileza de las noticias referidas a la violación de las normas y valores chilenos bien puede comprenderse entonces como la modalidad del discurso periodístico del racismo simbólico.

La historia actual de occidente, de la cual la frontera chileno-peruana forma parte importante aunque "periférica", demuestra que entre otras cosas las formas de 
referirse al inmigrante ha experimentado caminos similares a los recorridos por el "centro". Quienes hasta hace sólo unas décadas eran los potenciales enemigos de una guerra imaginaria hoy, por razones económicas, se trasformaron en parias de la urbe (Wacquant, 2001) cuando no directamente en lo que Agamben (1998) conceptualizó como homo sacer. Así, La Estrella, vista en clave de fuente histórica, da un pálido reflejo del símbolo negativo en que ha transformado al inmigrante peruano en Chile. No obstante, visualizar las pruebas documentales es una necesidad de primer orden para una Historia del Tiempo Presente, en mayúsculas, donde los historiadores parafraseando a Françoise Bédarida- deben tener un papel social superior al de un simple "creador de ilusiones" (p. 27).

\section{Referencias bibliográficas}

\section{Periódicos}

La Estrella (Arica, 2000-2010)

\section{Libros y artículos}

Abric, J-C. (2001). Prácticas sociales y representaciones. México: Ediciones Coyoacán. Agamben, G. (1998). Homo sacer. El poder soberano y la nuda vida. Valencia: Pre-textos. Almeida Vinueza, J. (1999). "Racismo, construcción nacional y mestizaje". En Almeida Vinueza, J. (Coordinador) (1999). El racismo en las Américas y el Caribe. Quito: Ediciones ABYA-YALA, pp. 189-210.

Alonso, S.; Volkens, A.; Gómez, B. (2012). Análisis de contenido de textos políticos. Un enfoque cuantitativo. Madrid: Centro de Investigaciones Sociológicas.

Araya, S. (2002). "Las representaciones sociales: ejes teóricos para su discusión”. En: Cuadernos de Ciencias Sociales, n. ${ }^{\circ}$ 127, pp. 1-83.

Araya Rodríguez, V.; Rivas Valdebenito, A.; Gasconi Martin, F. (2000). Creatividad e identidad en la prensa diaria ariqueña. Análisis histórico comparado del relato periodístico como constructor de identidad (1960-1990). Tesina (inédita), Arica: Universidad de Tarapacá.

Armentia Vizuete, J.; Caminos, J. (2008). Fundamentos de periodismo impreso. Barcelona: Editorial Ariel.

Aróstegui, J. (2004). La historia vivida: sobre la historia del presente. Madrid: Alianza Editorial.

Avendaño, C.; Krause Jacob, M. Y Winkler, M. I. (1993). "Representaciones sociales y teorías subjetivas: relevancia teórica y aplicaciones empíricas”. En: PSYKHE, n. ${ }^{\circ} 1$, pp. $107-$ 114.

Bédarida, F. (1998). "Definición, método y práctica de la Historia del Tiempo Presente”. En: Cuadernos de Historia Contemporánea, n. ${ }^{\circ}$ 20, pp. 19-27.

Bethell, L. (2000). Historia de América Latina. América Latina: Cultura y Sociedad. 18301930. Barcelona: Crítica, vol. n. ${ }^{\circ} 8$.

Browne Sartori, R.; Carvajal Rivera, J.; Salinas Oyarzo, R. (2011). “Análisis crítico del discurso: la prensa sensacionalista en contextos culturales colindantes. El caso de Ajá en Perú y La Cuarta en Chile”. En: Correspondencias \& Análisis, n. ${ }^{\circ}$ 1, pp. 263-267. 
Cárdenas, M. (2007). "Escalas de racismo moderno: propiedades psicométricas y su relación con variables psicosociales". En: Universitas psychologica, n. ${ }^{\circ} 6$ (2), pp. 255-262.

Ducci, M.e.; Rojas Symmes, L. (2010). "La pequeña Lima: Nueva cara y vitalidad para el centro de Santiago de Chile”. En: Revista Eure, n. ${ }^{\circ}$ 108, pp. 95-121.

Espelt, E.; Javaloy, F. (1997). "El racismo moderno”. En: S.O.S Racismo (Ed.), Informe anual sobre el racismo en el Estado español. Barcelona: EPSA.

Espina Prieto, R. Hacia una caracterización del prejuicio racial en Cuba. Algunos resultados del estudio del prejuicio racial en el escenario familiar. Disponible en la web: http://cubaarqueologica.org/document/ant04_rodrigo_espina.pdf. Recuperado: 17/11/2016

Fazio Vengoa, H. (1998). "La historia del tiempo presente: una historia en construcción”. En: Historia Crítica, n. ${ }^{\circ} 17$, pp. 47-57.

García Martínez, A. (2008). "Identidades y representaciones sociales: la construcción de las minorías”. En: Nómadas. Revista crítica de ciencias sociales y jurídicas, n. ${ }^{\circ} 18, \mathrm{p}$. s/d.

Gomis, L. (2008). Teoría de los géneros periodísticos. Barcelona: Editorial UOC.

Hogg, M. A.; Vaughan, G. (2008) Psicología Social. Madrid: Editorial Médica Panamericana. Huici, C. (1996). "Estereotipos”. En: MORALES, J. F.; HUCI, C. (Eds.). (2006). Psicología social y Trabajo social. Madrid: Mc Graw-Hill, pp. 175-200.

Javaloy, F. (1994). "El nuevo rostro del racismo". En: Revista Anales de Psicología, n. ${ }^{\circ} 10$, pp. 19-28.

Jodelet, D.; Guerrero, A. (2000). Develando la cultura. Estudios en representaciones sociales. México: Universidad Nacional Autónoma de México.

Lahoz I Ubach, S.; Forns I Santacana, M. (2016). "Discriminación percibida, afrontamiento y salud mental en migrantes peruanos en Santiago de Chile”. En: Psicoperspectivas. Individuo y Sociedad, n. ${ }^{\circ}$ 1, pp. 157-168.

Liberona Concha, N. (2015). "De las fronteras geopolíticas a las fronteras sociales. La migración boliviana a través de la prensa de Tarapacá (1990-2007)". En: Estudios fronterizos, n. ${ }^{\circ} 32$, pp. $41-74$.

Marková, I. (2006). "En busca de las dimensiones epistemológicas de las representaciones sociales”. En: PÁEZ, D.; BLANCO, A. (Eds.). (2006). La teoría sociocultural y la Psicología social actual. Madrid: Fundación Infancia y Aprendizaje, pp. 163-182.

Martini, S.; Luchessi, L. (2004). Los que hacen la noticia. Periodismo, información y poder. Buenos Aires: Biblos.

Mccombs, M.; Shaw, D. (1972). “The Agenda-Setting Function of Mass Media". En: The Public Opinion Quarterly, n. ${ }^{\circ}$ 2, pp. 176-187.

Moscovici, S. (2007). "Prefacio". En: ARRUDA, A.; ALBA, M. (Coords.). (2007). Espacios imaginarios y representaciones sociales. Aportes desde Latinoamérica. Barcelona: Anthropos.

Perera Pérez, M. (2003). "A propósito de las representaciones sociales. Apuntes teóricos, trayectoria y actualidad”. En: Revista del CIPS, n. ${ }^{\circ} \mathrm{s} / \mathrm{d}, \mathrm{pp} .1-35$.

Pérez, J.A. (1996). "Nuevas formas de racismo". En: Morales, J. Francisco y Yubero, Santiago (Coordinadores). (1996). Del prejuicio al racismo: perspectivas psicosociales. Cuenca: Publicaciones de la Universidad de Castilla-La Mancha, pp. 79-102.

Pérez Curiel, C. (2008). "Inmigrantes: hacia un nuevo modelo de ciudadanía. Radiografía de tópicos mediáticos y experiencias innovadoras”. En: Comunicación e ciudadanía, n. ${ }^{\circ} 6$, pp. 1-11.

Póo, X. (2009). "Imaginarios sobre inmigración peruana en la prensa escrita chilena: una mirada a la instalación de la agenda de la diferencia”. En: Revista F@ro, nº 9, pp. 1-9.

Randall, D. (2008). El periodista universal. Madrid: Siglo XXI de España Editores, S. A. 
Renkema, J. (1999). Introducción a los estudios sobre el discurso. Barcelona: Editorial Gedisa, S. A.

Rey Madrid, S. (2002). La construcción de la noticia: corrupción y piponazgo. Ecuador: Universidad Andina Simón Bolívar.

Rivera, C. (2000). El rol de la prensa escrita en el proceso de integración fronteriza: el caso de La Estrella de Arica y El Correo de Tacna. Tesina (inédita), Arica: Universidad de Tarapacá.

Sánchez García, F. J. (2010). Pragmática de los titulares políticos. Las estrategias implícitas de persuasión ideológica. Madrid: Visor Libros.

Shiappacasse Cambiaso, P. (2008). "Segregación residencial y nichos étnicos de los inmigrantes internacionales en el Área Metropolitana de Santiago". En: Revista de Geografía Norte Grande, n. ${ }^{\circ}$ 39, pp. 21-38.

Stefoni, C. (2002b). "Inmigración en Chile. Nuevos desafíos”. En: Anuario 2001-2002. Impactos y desafios de las crisis internacionales. Santiago: FLACSO.

- (2002a). "Mujeres inmigrantes peruanas en Chile". En: Papeles de población, n. ${ }^{\circ}$ 33, pp. 118-145.

Sunkel, G. (2001). La prensa sensacionalista y los sectores populares. Bogotá: Grupo Editorial Norma.

VAN DIJK, T. (1983). "Estructuras textuales de las noticias de prensa”. En: Anàlisi: Quaderns de comunicación i cultura, n. ${ }^{\circ}$ 7-8, pp. 77-105.

— (1996). “Análisis del discurso ideológico". En: Versión, n. ${ }^{\circ}$ 6, pp. 15-43.

- (2000). "El estudio del discurso". En: Van Dijk, Teun (Compilador). (2000). El discurso como estructura y proceso. Barcelona: Editorial Gedisa S. A., pp. 21-65.

Wacquant, L. (2002). Parias urbanos: marginalidad en la ciudad a comienzos del milenio. Buenos Aires: Editorial Manantial.

Ward, P. (2000). Raza y etnicidad en América Latina. Quito: Ediciones ABYA-YALA.

Wieviorka, M. (2002). El Racismo, una introducción. La Paz: Plural Editores. 